\title{
STUDENTS' PERCEPTIONS ON DISTANCE EDUCATION: A CASE STUDY IN MOZAMBIQUE
}

\author{
Alzira Manuel, Domingos Buque, Rosário Quive \\ Eduardo Mondlane University, Mozambique \\ E-mail: alziramanuel92@gmail.com, domingos.buque@gmail.com, \\ rosquive@gmail.com
}

\begin{abstract}
Education in all societies is one of the requisites for changes and development, particularly in the current context influenced by globalization and rapid changes in which knowledge and technology became essential tools for life. In this context, Mozambique has been and continues promoting education, including Classroom Teaching Adult Education and Distance Adult Education (DAE) to satisfy people's learning needs and improve their capacities towards changes. DAE is considered a way to open opportunities of education for youth and adults who by different reasons cannot participate in classroom teaching. This study seeks to explore the perceptions of youth and adult students in DAE at Eduardo Mondlane University (EMU), about their learning process. The study applied qualitative approach, based on semi-structured interview administrated to twelve students from the $3^{\text {rd }}$ and $4^{\text {th }}$ years of the undergraduate program in Organization and Management of Education in Distance Education (DE) modality. The findings of this study point out that DAE is perceived as a relevant and useful modality of education, particularly for adult learners. However, the study identifies contextual challenges associated to individual and professional issues, pedagogical and organizational issues as well as gender division of labor within the families, impacting the student's performance in DE in the selected higher education institution.
\end{abstract}

Keywords: adult education, distance education, lifelong learning, qualitative research

\section{Introduction}

Education is one of the ways to promote individual's capabilities, autonomy, increased participation in society and sustainable development. The right to education is not limited to children and youth. It also encompasses adults in different levels of learning, including higher education. Thus, DE is becoming part of educational policies aiming at increasing access to education, as many adults seek to continue their studies but due to different reasons, they are not able to participate in on campus-education. DE delivery in an approach of online education is a crucial learning opportunity "as it is easily accessible and facilitates close communication between teachers/tutors and students" (Carlsen et al., 2016, p. 28). Some of the reasons of increased demand for DE is the need of increased participation in society as a consequence of improved competencies and critical thinking. In this context, distance education modality is becoming one of the ways to help youth and adults to meet their rights. However, it is evident that DE "constitutes a barrier for who do not have access to equipment and internet" (Carlsen et al., 2016, p. 28). Given its important role in learning, DE must be accessible for all, including adults.

The role of adult learning and education is recognized in the Agenda 2030 for Sustainable Development. For instance, in the context of education, the goal four of this Agenda seeks to "ensure inclusive and equitable quality education and promote lifelong learning opportunities for all" (United Nations, 2016, p. 5). This purpose implies increased innovations and flexibility 
PROBLEMS

OF EDUCATION

IN THE $21^{\text {st }}$ CENTURY Vol. 79 , No. 2, 202

230

in the field of education. The traditional way of education and learning (classroom learning) is no longer enough to satisfy the needs of youth and adults as well as the increased demand for education. Therefore, DE is becoming a worldwide essential modality of education and it demands that people change their practices. That is, students and teachers must be keen to experience 'changing pedagogies' (Carrington \& Robison, 2009).

However, DE in the context of selected Mozambican university is characterized by different challenges (Brito et al., 2017; Mombassa \& Aruda, 2018) which can impact the quality of the program and concur for demotivation and drop out of the students. In this sense, the purpose of this study is to get insight of the youth and adult students' perceptions of DE on their learning process.

\section{Research Problem}

Distance Education is considered a modality that contributes for the increased educational, social, economic, and cultural inclusion in society, particularly in the case of Mozambique (Mombassa \& Aruda, 2019). It is one of the strategies for the reduction of inequalities, as classroom learning would not be able to provide learning opportunities to many people, mainly in rural areas (Mombassa \& Aruda, 2018), where around 70\% of population live, according to Instituto Nacional de Estatística - INE (2019). It is evident that the rapid development and expansion of Information and Communication Technology, and its application in education in Mozambique, increased the number of beneficiaries of DE (Mussa, 2010), particularly in higher education. DE is considered a modality that ensures access to different levels and types of quality education to many people (Universidade Eduardo Mondlane, 2013). It is also a modality that helps the inclusion of those who are not absorbed by the on-campus education modality of public higher education, due to its lack of capacity in developing countries, such as Mozambique. Despite the increased expansion and relevance of this type of education, different constraints seem to interfere in its goals.

In fact, constraints affecting learning programs have been pointed in different studies in online and classroom learning in Mozambique and other developing countries. In Mozambique, Mombassa and Aruda (2018) refer to the need of teachers' competencies improvement in DE at universities and design of a national policy that can promote this modality. Universidade Eduardo Mondlane (2013), amongst different challenges in DE, in this institution, points out pedagogical, organizational, and technological aspects impacting the quality of this learning modality. In their turn, Manuel et al. (2015) in the study about non-formal vocational education and training in Mozambique, amongst other aspects, concluded that pedagogical aspects, including the improvement of teacher's competencies and administrative aspects in these programs need to be improved.

Similarly, the study carried out in South Africa, (Baijnath \& Butcher, 2015) quoted by Prinsloo (2019), concluded that the great challenges of online DE in South Africa include "the infrastructures and limited bandwidth, political and cultural factors, student access to devices, a commitment to new learning model and developing staff capacity" (p. 77). Regarding cultural facts, Muiru and Mukuria (2005) pointed out the existence of 'pockets of cultural conservatism' in Kenyan communities as a factor impeding women to fully participate in learning programs. Accordingly, "parental preference for a wife and mother role for daughters" has a "pervasive influence on the situation of women" (op. cit., p. 94). All these aspects may hinder the main objective of education, in this case, the objectives of DE that are linked to the promotion of inclusive quality education towards social justice, change and development. 
DE is becoming an important modality of education in the world. Its characteristic of flexibility helps many youth and adults who cannot participate in on-campus education. In this sense, DE contributes to the increased access to education, promoting in this way, educational inclusion, especially in the context of developing countries, where access to education through classroom modality is still a great challenge for the governments. According to Musingafi et al. (2015, p.59), "Zimbabwe acknowledge the importance of open and distance learning in bringing higher education to the disadvantaged groups like women and disabled".

$\mathrm{DE}$ can be defined in different ways, one of them being that it is a self-directed, autonomous learning experience, based on technology that connects learners with resources, instructors, out of formal institution (Johnston, 2020). However, a single definition cannot embrace all the experiences of this modality of education. DE can also be defined as an instructor-led learning experience employing technology to expand the synchronous classroom experiences across distances (Johnston, 2020). While the first definition suggests high autonomy and flexibility amongst students, the second one underlines the existence of an instructor as facilitator of the learning process, with the learners at the heart of it. The major advantages of DE, particularly for youth and adult learners are linked to its characteristics of "flexibility, accessibility, affordability and life-based education opportunities" (Musingafi, 2015, p. 59).

Research reveals that "the trends in the field of DE shifted in pedagogical perspective and theoretical frameworks with student interaction at the forefront become beating heart of learner-centered strategies and environment" (Carlsen et al. 2016, p. 49). The learning methods in DE open up the possibility for students to "start studies whenever they want" (or they can) (Carlsen, et al., 2016, p. 28). This aspect is a benefit for adult learners who are often involved in different responsibilities, which can constitute a barrier for their continuing learning process. This advantage turns DE into a fundamental part of higher education (Tucker, 2001), mainly in recent era where information and technology are becoming essential elements for social and economic life.

The increased technological development that influences the world demands increased need of education, and simultaneously introduces profound changes on it. According to the Strategy of Distance Education, in Mozambique (Universidade Eduardo Mondlane, 2013) the progress of $\mathrm{DE}$ is linked to the challenges brought by the rapid development of technology that allows the creation of virtual environments for the increased interaction between different actors of the education process. DE is one of the strategies of promoting learning amongst adults, which is essential in nowadays context of rapid changes and development. Currently, in the context of Mozambique, DE emerges as an opportunity to expand access to education, particularly higher education (Mombassa, 2019).

According to UNESCO (2010), adults who prolong their education have great access to information and knowledge needed to improve their work and their life, contributing for continuing positive changes, at individual, familiar and social dimensions. This demonstrates the power of lifelong learning, with learning not as a commodity but as a way to enrich people's biography (Jarvis, 2007).

\section{Theoretical Considerations}

\section{Lifelong Learning in the Context of Adult and Continuing Education}

Lifelong learning is a perspective that contributes for the increased social, cultural, economic, and political participation in society. Learning is related to changes and changes require learning throughout individual's life. In this sense, London $(2012, p .1)$ explains that 
PROBLEMS

OF EDUCATION

IN THE $21^{\text {st }}$ CENTURY Vol. 79 , No. 2, 2021

232

"change imposes gaps between what is and what is going to be, or between what was and what is now". It is this difference that moves people to engage in learning activities. Otherwise, they "are likely to be mired in the past, perhaps struck alone on a plateau other move away and ahead..." (Idem, p. 2). Learning promotes social inclusion, as the life in society is always changing, and people need to be aware about how they must behave, what they need to know, to ensure their participative citizenship.

According to Jarvis (2007, p. 5), "in contemporary society the life-world changes so rapidly $(. .$.$) it is never static ..." thus, people need frequently to learn to be able to adjust$ themselves to the changes and to promote transformations, and "find their place in society". Learning creates new competencies and opens new possibilities and new opportunities, which could not be tangible without the needed capabilities. These capabilities can be developed in different contexts according to the concrete needs of each individual or group of individuals. Thus, lifelong learning encompasses all types of educational and learning experiences, for adult, aiming to improve their knowledge, skills, and critical thinking abilities (Ahmed, 2014).

In this perspective, "lifelong learning or continuous learning is often viewed as the domain of adult or continuing education" (London, 2012, p. 2). Lifelong learning is also considered a way of opening up opportunity for individuals to continually learn "to enhance their knowledge and skills in order to address immediate problems and to participate in a process of continuous vocational and professional development" (Idem, p. 3). For instance, Kasworm (1993, p. 412) noted that "Adult participation in higher education has come to symbolize one important aspect of the learning society" and sustains that there are many reasons that motivate the necessity for adult access and participation in higher education, among which, "the need for significant expansion of educational opportunities for adult due to the short viable life of current knowledge...", that affects all societies in the umbrella of globalization.

\section{Research Methodology}

\section{General Background}

The present research is qualitative and exploratory, focusing on perceptions and experiences of youth and adult learners in distance higher education in the chosen university, on the period 2016-2019. "Qualitative research tends to be associated with small-scale studies" (Denscombe, 2003, p. 233).

\section{Research Sample}

For the selection of respondents, purposive sampling was used. This sampling procedure is not strictly prescribed, and the researcher selects the respondents according to the objective and the formulated research questions. According to Creswell and Plano Clark (2011), purposive sampling implies the identification and selection of respondents or groups of respondents that are clearly familiar or experienced with a phenomenon under study. In this study, the sample is composed of twelve students, being six from the $3^{\text {rd }}$ and six from the $4^{\text {th }}$ years of the undergraduate program in Organization and Management of Education, in DE modality. Amongst them, seven are males and five females. The selection of the students from two different levels was for the purpose of triangulation of their perceptions.

\section{Instruments and Procedures}

This study used semi-structured interview that was applied to the selected students. The data collection was carried out in November, December 2019, and February 2020, before the 
spread of COVID 19 pandemic in Mozambique. Thus, it was possible to perform face-to-face interviews, with the respondents. The first contact with the students was by phone and it served to schedule the interview. Then, semi-structured interview was applied to collect their perceptions and experiences about their learning process and context. The selection of the respondents was also dependent on their geographical location and availability, as most of them live far from the university. The interview was carried out and analyzed in Portuguese and only the excerpts used in the results section were translated into English, as quotations. The translation of the respondents' sayings from Portuguese into English can be considered one of the limitations of this research, as the original words may have been affected.

\section{Data Analysis}

After data collection, the interviews were transcribed verbatim. According to Denscombe (2003, p. 183), the transcription of data is "a very valuable part of research because it brings the researchers close to the data". In fact, the transcription process during this study allowed getting in mind the different ideas expressed by the respondents and to understand their focus before data analysis. The data transcribed were read repeatedly to understand their meaning, and content analysis method was used. In this sense, after the process of familiarization with the data, these were interpreted, and similar information was grouped and coded. Bengtsson (2016), explaining how to perform qualitative study using content analysis, advocates the need of using the coding list and clarification notes of the codes to reduce a cognitive change during the process of analysis. This procedure contributed for trustworthiness, which is fundamental in research. Later, the grouped data and their codes were interpreted and some of the data were reduced, taking into account the objective of the study. Then, the categories emerged.

\section{Ethical Considerations}

To meet ethical procedures, in the first contact with the students, they were given explanation on the purpose of the research and asked about their willing to participate in it. Later on, the interview schedule was negotiated with them and the interview was carried out at the university. Aiming at avoiding any personal harm, the names of the respondents were replaced with a "R" (Respondent), followed by a number according to their position in the list of interviews.

\section{Research Results}

The data collected and analyzed conducted to the following categories: General perceptions about Distance Education, Individual, professional and gender division of labor, Pedagogical and Organizational issues.

\section{General Perceptions about Distance Education}

The students from $3^{\text {rd }}$ and $4^{\text {th }}$ year included in this study perceived DE as a useful modality of education that contributes to expand access to education. In this perspective the R1 pointed out that "it allows people to study wherever they are... as long as there is internet signal" and allowed conciliation of studies with employment as "there is no need to go to university, [having to go there] only in the period of examinations".

Apart from the perceptions linked to increased access to education, R2, understanding the increased role and importance of Information and Communication Technology (ICT), considered DE as a way to improve people's competencies in this matter, while interacting 
PROBLEMS

OF EDUCATION IN THE $21^{\text {st }}$ CENTURY Vol. 79, No. 2, 2021

234

in the learning program. This modality is also considered one of the ways of improving communication and negotiation skills. For instance, R8 noted that "many times it was necessary to negotiate with the lecturers the schedule of the classes and assessments" and "the interaction during the class, improves the capacity of discussing important topics respecting the ideas of others". R4 saw the pedagogical advantage of DE as he noted that "Distance Education allows the implementation of student-centered learning approach (...) it ensures that students prepare their lessons and participate actively in the learning process interacting with the lectures and the colleagues".

The perceptions that DE contributed to improve different competencies were repeatedly registered in this research. For instance, R1 noted that DE improved some psychological capacities such as "sense of responsibility and the interest in reading". In summary, according to this research, DE contributes for increased access to education, particularly adult education, improves student's competencies in ICT and in negotiation skills and promotes student centered learning approach.

\section{Individual, Professional and Gender Division of Labor}

The respondents in this study noted that sometimes they did not have enough time to carry out their tasks in the context of their studies due to the demand of work in the schools they taught, especially in the period of examinations. One of the respondents explained that it happened that when he could get time to do the tasks, the deadline had expired and the system had closed, therefore he could not send the task on time and he failed the module.

Another problem pointed out was the weak internet signal in their residential areas or workplace. R4 explained: "due to weak internet signal I used to climb the mountain trying to find the internet ... because from there it seems easy".

The problem of lack of internet signal was mentioned by the respondents as one of the major challenges, as it impacted the learning process, in individual and collective way as R4 clarified: "...sometimes we did not have class due to the weak internet signal". R6 noted that "the internet is a huge barrier; sometimes teachers give us homework with deadlines; if at the time of submitting the task the internet is weak or oscillating, it is not possible to send the work, and this impacts our pedagogical results".

Still in this category, R5 explained that most of her colleagues of the DE program at the university were teachers in Primary Education schools. They worked at the districts, far from their families, and they used to go home only on Fridays, to visit their families. In her words: "on Friday I don't have time to prepare my classes because I use to be focused on my trip back to home". R5 added: "on Friday I use to attend the class being in "My love" going home and in some places, there is no internet signal...between the village and the city...". ("My love" is a local popular denomination of a small lorry that serves as a semi-collective bus, and passengers travel standing and supporting each other).

The study also demonstrated that issues linked to gender division of labor within the families also constituted one of the challenges amongst women during the learning process. For instance, R3 noted that "If someone [woman] goes home before concluding her academic tasks no one will understand [at home] that tasks linked to her studies must be done...". Similar perception was also expressed by R5, who said: "when I have many tasks with deadlines, I must solve them at home, where I have children to take care, familiar programs to attend and the general domestic work to carry out... all these activities on Saturday, because Sunday I must go back to the locality where I work ... this is painful."

In summary, the respondents expressed challenges linked to the demand of work in the schools where they taught, the problems linked to the weak internet signal in their residential areas or workplace. Furthermore, female respondents brought other challenges related to their socio-cultural environment of gender division of labor, impacting their learning process. 
The pedagogical issues were pointed out in different perspectives by the students from the $3^{\text {rd }}$ and $4^{\text {th }}$ years. For instance, R3 noted that the way lecturers used to send the reading material was a challenge as some lecturers, instead of sending the basic material electronically in the platform, they only sent the topics and the respective links. According to her "it is true that students must be able to search information in Google, but what happens is that not all of us can easily find the material through links, due to the slowness of internet...at the district!"

In the category of pedagogical issues, the lack of feedback during the learning process was pointed out as the respondents perceived that the feedback on formative assessments was almost inexistent. In the words of R5: "usually the lecturers do not give us... feedback about our work, during the learning process, they only publish the preliminary pedagogical results, and we do not know where we did wrong or why we got 10..." (The maximum classification is 20 marks in the case of Mozambique). Apart from lack of feedback, students also noted the delayed publication of the pedagogical results, at the end of the modules. This could negatively impact their performance in the examination phase, as R8 said: "Some lecturers delay the publication of the pedagogical results at the end of the module (...) sometimes we have the final examination on Saturday and the lecturers inform the results the day before, on Friday (...) and students who must write the examination do not have enough time to prepare themselves effectively".

Besides these issues, the pedagogical concerns linked to the lack of interaction between the supervisors and the students in the phase of elaboration of the monograph were also pointed out. For instance, R5, student from the $4^{\text {th }}$ year, explained “....Him! I feel difficulties in the phase of monograph ...I have finished the curricular part in 2017, but until now [2019] I did not finish my monograph...it looks like my supervisor is always busy..." In the same perspective, R10 noted that some lecturers imposed the need of hard copies of the text of monograph during the process of supervision while the course was at distance, as he said: "...the classes are at distance, but some lecturers require the supervision to be done face-to-face and the monographs to be sent in hard copy... This is difficult for the students as they must print out the text of their monograph several times and have to travel for supervision..."

In this study, the organizational concerns were also perceived in terms of slowness of response to the student's requests. For instance, R12 revealed: "I...I have submitted documents to get the certificate of the modules that I have concluded, a year ago, until now it is not ready".

In this category, the respondents brought different issues, such as lecturers sending topics and links, instead of the basic learning material. This became difficult for students to access those links due to the weakness of the Internet signal, lack of feedback related to the formative assessment, which had influence in students' progress and development, delayed information of the results before the examination, leaving students without enough time for their effective preparation, lack of interaction between the supervisors and the students in the phase of monograph (this is one of the aspects that contributed for the delayed conclusion of the course) and compulsory face-to-face supervision, when the classes were on distance modality.

\section{Discussion}

$\mathrm{DE}$ is seen by the respondents of this research as a helpful modality of education that contributes to expand access to education to many youth and adults who otherwise would not get opportunity to participate in learning programs, particularly higher education in rural areas. In the context of Mozambique, in rural areas there are no institutions of higher education. These institutions have their premises in big cities. This constitutes a source of exclusion for many youth and adults, who work and live in rural areas. In this context, DE opens up new 
PROBLEMS

OF EDUCATION IN THE $21^{\text {st }}$ CENTURY Vol. 79 , No. 2, 2021

236

opportunities for people from rural areas, and many other citizens, becoming, as Tucker (2001) concludes, a very important part of higher education.

The respondents of this study perceive DE as contributing for the improvement of people's competencies on Information and Communication Technology (ICT), an essential tool for life in the $21^{\text {st }}$ century, in which "people are always becoming" (Jarvis, 2010, p.39). In fact, during the learning process, through interaction with technology, instructors and learning content, students have an opportunity to improve their knowledge, skills, and positive attitude in relation to ICT. Apart from these perceptions, it was noted that DE, due to its teaching and learning methodology, which demands the involvement of students as subjects of their own learning process, promotes student centered learning. This learning methodology is a basis for the development of autonomy and critical thinking, which are important requisites for life in the context of rapid social, economic, political, and technological changes that characterize all societies.

According to Jarvis (2007, p. 17), "society is changing so rapidly that many of the traditional education organization (and its traditional methods) are not able to keep abreast with the new demands..." In this context, the sense of responsibility is also developed in the context of DE given that the students, as youth and adults, have enough space to control their own learning process. However, DE in developing countries context, as it is the case of Mozambique, is embedded in many different constraints, which can hamper its quality and relevance. This study points out constraints linked to the students themselves, constraints brought by their profession and constraints linked to socio cultural issues within their families (gender division of labor) and pedagogical and organizational constraints. Individual and professional constraints are linked to the fact that the respondents of this study are also teachers in primary schools and regularly they have to apply assessments to their pupils, and at the end of the year, obviously, they have to apply and mark exams. Thinking that in the Mozambican context, in public education, classes of primary and secondary schools are composed of around thirty to sixty pupils, it is obvious that professional issues interfere in the learning process of student teachers.

One of the most pointed aspects that constitute a big challenge in DE is the weak internet signal in the villages, where the students work and live during the week (they live and teach at the district, but all of them come from the city and they go back on Friday). Internet has been one of the factors that impede students to comply with the deadlines for assessment submission. Consequently, some of them must repeat the assessment in some modules or simply they fail.

Issues linked to gender inequality, gender division of labor were noted as part of the challenges for women students, within their families. Some families do not understand that women, just as the men, have the need and the right to improve their capacities through formal education regardless of being adult, married and mothers. These families constitute 'pockets of cultural conservatism' (Muiru \& Mukuria, 2005). In this sense, female students face great challenges when they need to cope with their academic tasks during the weekend at home. They perceive that they have many domestic tasks to carry out and sometimes they are not able to meet the deadlines for submission. This situation affects their performance as students, contributes for the delayed completion of the course and can contribute for student's demotivation and drop out.

In this study, pedagogical and organizational concerns were also pointed out. Students perceive that during the learning process their lecturers must provide them with feedback. In whatever learning process, feedback is of great importance as it is part of formative assessment and instructors, as facilitators, must provide each student with this information. Feedbacks during the learning process allow students to understand what they know and what they need to improve. Thus, feedback is one of the requisites for competencies development during the learning process. 
In the same perspective, students also perceive that in some modules the pedagogical results are announced belatedly, sometimes only one day before the examination. This result is similar to the study carried out in Zimbabwe (Musingafi, et al., 2015, p. 65) that pointed, as instructional related challenges "ineffective and delayed feedback of students' assignments..." This constitutes a constraint for those students who need to prepare themselves for the examination and can be one of the factors for low pedagogical results and repetitions. In this matter, lack of interaction between some students and some supervisors was pointed out as one of the reasons for the delayed conclusion of the program. It is possible that some supervisors are busy with other tasks at the university, and the students, being teachers themselves, use to be engaged in many teaching activities at school lacking time to carry out their tasks as students.

However, some of the students who have interaction with their supervisors see that while the classes are through distance modality, the supervision is planned to be face-to-face and the monograph sent in hard copy. Clearly, there is a need of 'changing pedagogies' (Carrington \& Robison, 2009) among these lecturers/supervisors. This practice constitutes a barrier for some students since they live and work far from the university, and the cost of the trip to and from campus as well as the printing of their work for discussion with the supervisor is high and sometimes the students did not plan this additional cost. If it is argued that DE is made feasible at a distance by means of media which can cover extensive distances (Johnston, 2020), students and supervisors need to negotiate strategies of interaction that can be practical for both to allow quality of their work and a smooth interaction. The study also noted that the provision of documents, such as certificates, comes as a challenge to the students; they must wait almost a year when they request their certificates. This can be a signal that, nevertheless the different efforts towards changes, there is a need of improved communication between the different actors that collaborate in DE and an improved coordination towards quality services and effectiveness. Similarly, Mombassa and Aruda (2019), in the study about DE in Mozambique, remarked that the challenge of $\mathrm{DE}$ is in changing mentality of all university community towards an effective DE. Musingafi et al. (2015) in the study 'on open and distance learning' came to the similar conclusion as they noted that this modality has "inadequate academic support and administrative services. In spite of some similarities with the results of the consulted studies, this study brought some novelties as, for instance, the understanding that sociocultural issues linked to unequal division of labor within households has a negative impact in the performance of women in education, in DE, nevertheless it is seen as the modality that can promote educational inclusion.

This study, despite the size of the sample, provided a deep understanding of the perceptions of students in DE relatively to their learning context and process.

\section{Conclusions and Implications}

The purpose of this research was to get insight of the perceptions of youth and adult students of DE at Eduardo Mondlane University, about their process of education. The research concludes that $\mathrm{DE}$ is seen as an important and relevant educational modality that contributes for the provision of educational opportunities for many youth and adults, especially in higher education.

DE allows participation in educational programs irrespective of the place people are. This is an added value as many youth and adults work and live far from the cities, where the universities are located, and they need to continue learning to improve their competencies, particularly in this context of rapid changes in which learning is becoming part of life.

Nevertheless, the positive perception of DE, this modality is also embedded in different constraints that can interfere in its quality, as they impact the students' active participation and effective learning. This study noted that the demand of work in the schools where the respondents are teachers negatively impacts their process of learning as DE students. This 
PROBLEMS

OF EDUCATION IN THE $21^{\text {st }}$ CENTURY Vol. 79 , No. 2, 2021

238

means that in their context of work they do not have enough space to negotiate their schedule considering their studies. This situation may be a result either of teachers' shortage, in schools or of unbalanced power relations between the teachers and the school managers, interfering in their work relations.

The weak internal signal in some regions impacts the learning process particularly in relation to the process of searching the learning material. Apart from these challenges, the study revealed that external factors such as the socio-cultural environment in the households characterized by gender unequal division of labor, in which females are fated to carry out all household tasks, interfere in the learning process and progress of women in DE. The study also noted that pedagogical and organizational issues need to be improved, particularly in relation to feedback provision to the students after the formative assessments.

Lecturers must provide feedback related to formative assessments to help students to understand where they are or what they know and where they must arrive or what they need to improve. Feedback contributes for the students' self-confidence and autonomy. Therefore, it is relevant in the learning process. Similarly, interaction between supervisors and students in the phase of monograph writing should be active to allow students to conclude their studies within the planned period. However, this issue is also dependent on the students' competencies, interest, availability, and flexibility. Finally, the study noted that coordination and communication between administrative sector and pedagogical need to be improved to offer quality and flexible services to the students.

In summary, the study concludes that DE is a way to provide new learning opportunities to people, particularly young and adult people who are, in general, involved in other activities or who live far from the cities and are not able to participate in on campus learning modality. However, the study brought challenges that are perceived by the selected students. These challenges can be categorized in external and internal challenges. Internal challenges are considered all those located outside the university context. They are related to individual, professional and gender division of labor; and internal challenges are considered those linked to pedagogical and organizational issues, within the learning process and within the university.

\section{References}

Ahmed, M. (2014). Lifelong learning in a learning society: Are community learning centres the vehicle? In G. Carbonnier, M. Carton, \& K. King (Eds.), Education, learning, training: Critical issues for development (pp. 102-125). Brill-Nijhoff.

Bengtsson, M. (2016). How to plan and perform a qualitative study using content analysis. NursingPlus Open, 2, 8-14. https://doi.org/10.1016/j.npls.2016.01.001

Brito, C., Mondjana, Ana Maria, Santos, L., \& Khan, M. (2017). O ensino à distância (EaD) na Universidade Eduardo Mondlane (UEM): Situação actual e desafios. [Distance learning (DL) at Eduardo Mondlane University (EMU): Current situation and challenges.] Universidade Eduardo Mondlane (UEM). https://pdfslide.tips/documents/o-ensino-a-distancia-ead-na-universidadeeduardo-solucao-de-curto.html

Carlsen, A., Holmberg, C., Neghina, C., \& Owusu-Boampong, A. (2016). Closing the gap: Opportunity for distance education to benefit adult learners in higher education. UNESCO. https://unesco.org/ ark:/48223/pdf0000243264

Carrington, V., \& Robinson, M. (2009). Digital literacies: Social learning and classroom practices. UKLA/SAGE.

Creswell, J., \& Plano Clark, V. (2011). Designing and conducting mixed methods research ( $2^{\text {nd }}$ ed.). Sage Publications.

Denscombe, M. (2003). The Good Research Guide for small-scale social research projects ( $2^{\text {nd }}$ ed.). MacGraw-Hill Education.

INE (2019). Resultados definitivos do Censo 2017. IV recenseamento geral da população e habitação [Final results of the 2017 Census. IV general population and housing census]. Instituto Nacional de Estatística. 
Jarvis, P. (2007). Globalization, lifelong learning and the learning society: Sociological perspectives (Vol. 2.). Routledge.

Jarvis, P. (2010). Adult education and lifelong learning: Theory and practice (4 $4^{\text {th }}$ ed.). Routledge.

Johnston, J. P. (2020). Creating better definitions of distance education. Online Journal of Distance Learning Administration, 23(2). https://eric.ed.gov/?id=EJ1260793

Kasworm, C. (1963). Adult higher education from an international perspective. Higher Education, 25, 411-423.

London, M. (2012). Lifelong learning: Introduction. The Oxford Handbook of lifelong learning. https://doi:10.1093/oxfordhb/9780195390483.013.0013

Manuel, A., Popov, O., \& Buque, D. (2015). Towards programme improvement in non-formal vocational education and training in Mozambique. Problems of Education in the 21st Century, 67, 61-71. http://www.scientiasocialis.lt/pec/node/985

Mombassa, A., \& Arruda, E. (2018). História da Educação à distância em Moçambique: Perspectivas actuais e as contribuições do Brasil. [History of distance education in Mozambique: Current perspectives and contributions from Brazil]. Praxis Educativa, 13(3), 643-660.

Mombassa, A., \& Aruda, E. (2019). Educação à Distância em Moçambique: Perspectivas para a inclusão da população no ensino superior. [Distance education in Mozambique: Perspectives for the inclusion of the population in higher education]. Revista Diálogo Educação, 19(61), 899-919.

Muiru, J., \& Mukuria, G. (2005). Barriers to participation in Adult Literacy Programs in Kenya. Adult Basic Education, 15(2), 85-102.

Musingafi, M., Mapuranga, B., Chiwanza, K., \& Zebron, Sh. (2015). Challenges for open and distance learning (ODL) students: Experiences from students of the Zimbabwe Open University. Journal of Education and Practice, 6(18), 59-66.

Mussa, J. (2010). Educação a distância em Moçambique: Um contributo para o "estado de arte". [Distance education in Mozambique: A contribution to the "state of the art"]. Universidade do Minho. https://www.academia.edu/3348035/Educa\%C3\%A7\%C3\%A3o_a_dist\%C3\%A2ncia_ em_Mo\%C3\%A7ambique_um_contributo_para_o_estado_da_arte

Prinsloo, P. (2019). South Africa. In Zawacki-Richter, $\overline{\mathrm{O}}$., \& Qayyun, $\overline{\mathrm{R}}$. (Eds), Open and distance education in Asia, Africa and Middle East. Springer Briefs in open and distance education. https:// doi.org/10.1007/978-981-13-5787-9-1

Tucker, Sh. (2001). Distance education: Better, worse, or as good as traditional education? Online Journal of Distance Learning Administration, 4(4). https://eric.ed.gov/?id=EJ643442

Universidade Eduardo Mondlane (2013) Estratégia de Educação à distância 2014-2018. [Distance Education Strategy 2014-2018]. Centro do Ensino à Distância, UEM.

United Nations (2016). The sustainable development goal report. New York. https://unstats.un.org/sdgs/ report $/ 2016 /$ The $\% 20$ Sustainable\%20Development $\% 20$ Goals\%20Report\%202016.pdf

UNESCO (2010). Relatório Global sobre aprendizagem e Educação de Adultos. [Global Report on Adult Learning and Education]. UNESCO.

Received: January 13, 2021

Accepted: March 22, 2021 
Alzira MANUEL, Domingos BUQUE, Rosário QUIVE. Students' perceptions on distance education: A case study in Mozambique

PROBLEMS

OF EDUCATION

IN THE $21^{\text {st }}$ CENTURY

Vol. 79, No. 2, 2021

Cite as: Manuel, A. A. M., Buque, D., \& Quive, R. (2021). Students' perceptions on distance education: A case study in Mozambique. Problems of Education in the $21^{\text {st }}$ Century, 79(2), 229-240. https://doi.org/10.33225/pec/21.79.229

Alzira A. M. Manuel

(Corresponding author)
PhD, Lecturer, Eduardo Mondlane University, Patrice Lumumba Av. No 207, 1100 Maputo, Mozambique.

E-mail: alziramanuel92@gmail.com

ORCID: https://orcid.org/0000-0002-9991-7358

$\mathrm{PhD}$, Lecturer, Eduardo Mondlane University, Mozambique.

E-mail: domingos.buque@gmail.com

Master, Retired Lecturer, Eduardo Mondlane University, Mozambique.

E-mail: rosquive@gmail.com 